\title{
Texture evolution by shear on two planes during ECAP of a high strength aluminium alloy
}

\author{
Shun Cai Wang ${ }^{1 *}$, Marco J. Starink ${ }^{1}$, Nong Gao ${ }^{1}$, Xiao Guang Qiao ${ }^{1}$, \\ Cheng $\mathrm{Xu}^{2}$; Terence G. Langdon ${ }^{1,2}$ \\ ${ }^{1}$ Materials Research Group, School of Engineering Sciences \\ University of Southampton, Southampton SO17 1BJ, U.K. \\ ${ }^{2}$ Departments of Aerospace \& Mechanical Engineering and Materials Science \\ University of Southern California, Los Angeles, CA 90089-1453, U.S.A.
}

\begin{abstract}
The evolution of texture was examined during equal-channel angular pressing (ECAP) of an $\mathrm{Al}-\mathrm{Zn}-\mathrm{Mg}-\mathrm{Cu}$ alloy having a strong initial texture. An analysis of the local texture using electron back-scatter diffraction demonstrates that shear occurs on two shear planes: the main shear plane (MSP) equivalent to the simple shear plane, and a secondary shear plane which is perpendicular to the MSP. Throughout most regions of the ECAP billet, the MSP is close to the intersection plane of the two channels but with a small $\left(5^{\circ}\right)$ deviation. Only the $\{111\}<110>$ and $\{001\}<110>$ shear systems were activated and there was no experimental evidence for the existence of other shear systems. In a small region at the bottom edge of the billet that passed through the zone of intersection of the channels, the observed textures were fully consistent with the rolling textures of Copper and Goss.
\end{abstract}

Key words: aluminium alloy; electron back-scatter diffraction; equal-channel angular pressing; shear planes; texture.

*Corresponding Author: Shun Cai Wang: Tel: +44-23-8058 4638. E-mail: wangs@soton.ac.uk 


\section{Introduction}

Equal channel angular pressing (ECAP) is at present one of the most promising techniques for processing bulk ultrafine-grained materials sufficiently large that they may be used for structural applications [1]. During the last two decades, ECAP has progressed from a relatively minor metal processing technique to become a well-established and recognized procedure for achieving very significant grain refinement in a wide range of metallic alloys.

In processing by ECAP, a sample is pressed repetitively through a die in which two channels of equal cross-section intersect at an angle $\Phi$ [1-4]. The design of the die may use a configuration in which the intersection of the two channels causes an abrupt change of direction (a 'square' die design) or it may have an arc of curvature at the outer point of intersection between the two channels as shown in Fig. 1(a) where this outer angle is labelled $\psi$. The influence of the die channel angle has been investigated using pure aluminium and the results show that an angle of $\Phi$ close to $90^{\circ}$ represents the optimum condition for achieving excellent grain refinement and a large fraction of boundaries having high angles of misorientation [5]. Finite element modelling of the ECAP configuration with $\psi=0^{\circ}$ shows that, at angles close to $\Phi$ $\approx 90^{\circ}$, it is difficult to completely fill the die corner when pressing less ductile materials except under conditions where a back pressure is applied at the point of exit from the die [6]. These difficulties may be reduced in practice by increasing the channel angle and/or the strain rate sensitivity of the material [7].

The texture evolution in ECAP was modelled in several reports [8-11]. This work has been based on the notion that, under ideal ECAP conditions, the deformation occurring in ECAP may be approximated by simple shear along a single plane crossing the ECAP channel $[12,13]$ where this plane corresponds to the intersection of the two channels lying perpendicular to plane $\mathrm{Y}^{\prime}$ in Fig. 1(b). A polycrystalline alloy responds to the macroscopic shear stress by deformation of individual grains through movement of dislocations on one or more of the crystallographic slip planes $\{\mathrm{hkl}\}$ that are favourably oriented, combined with the rotation of grains to directions that bring the main crystallographic slip planes parallel to the macroscopic shear direction and the crystallographic slip directions $<u v w>$ parallel to the main shear direction. The balance between these two processes is dependent on several factors including the flow strength on the slip systems, the resistance to grain rotation and the grain size. Four ideal shear systems have been proposed for the torsion straining of f.c.c. structures as listed in Table 1 [14] and it is reasonable to consider that ECAP is an analogous processing procedure.

Several reports on modelling of the texture evolution during ECAP assume the existence of all four shear systems as listed in Table 1 [8-11]. Thus, all of the models consider shear in one shear direction and, in order to explain the observed textures, all four shear systems must be included. The present work was motivated by the realisation that at least one of these shear systems, the system designated $\mathrm{A}^{*}$, is unlikely to occur in practice. This is because the Burgers vector or slip direction in f.c.c. aluminium at strains up to about 1 and temperatures below about $200^{\circ} \mathrm{C}$ is more commonly assumed to be exclusively the $1 / 2<110>$, as a classical analysis of slip in f.c.c. structures indicates, and, furthermore, there is no direct experimental evidence to confirm the existence of $1 / 2<112>$ as a relevant Burgers vector in aluminium alloys for any type of deformation. Following a classical analysis of slip in f.c.c. crystals, it follows also that the $\{112\}<110>$ shear system is less likely.

In the present investigation, it is demonstrated that the development of texture during ECAP may be explained without recourse to the assumption of a $1 / 2<112>$ Burgers vector. Accordingly, experimental data and analysis are presented for texture evolution in an extruded 
commercial A1-7034 alloy after one pass of ECAP. Electron back-scatter diffraction (EBSD) is applied to provide the texture data.

\section{Experimental materials and procedures}

The experiments were conducted on a spray-cast Al-7034 alloy containing, in wt. \%, $11.5 \% \mathrm{Zn}, 2.5 \% \mathrm{Mg}, 0.9 \% \mathrm{Cu}$ and $0.2 \% \mathrm{Zr}$ with the balance Al. The Al-7034 alloy was received in the form of an ingot and extruded into a rod. In this condition, the average grain size was 2.1 $\mu \mathrm{m}$. Processing was conducted by ECAP using a solid die with an internal channel having a diameter of $10 \mathrm{~mm}$, with the channel bent through $\Phi=90^{\circ}$ and with an outer arc of curvature of $\psi=20^{\circ}$. Fig. 1(a) shows a schematic illustration of a billet before and after a single pressing through the die. No back pressure was applied in the present work other than the limited pressure that arises in repetitive pressing as sequential billets move through the die. The Al-7034 is a high strength alloy and hence billets were pressed at an elevated temperature of $473 \mathrm{~K}$. Earlier studies using electron microscopy and optical microscopy showed the alloy contains a high fraction of $\eta$ phase based on $\mathrm{Mg}_{2} \mathrm{Zn}$ [15].

To analyse the texture evolution, EBSD measurements were taken in an FEG-SEM JEOL 6500F instrument using an automated EBSD system (Channel 5 HKL) with a step size of 0.05 $\mu \mathrm{m}$ at an accelerating voltage of $15 \mathrm{kV}$ and a beam current of $10 \mathrm{nA}$. The EBSD specimens were electro-polished prior to examination using a solution of 33\% nitric acid in $67 \%$ methanol. The EBSD data were acquired from the cross-sections of an as-received billet and from a billet after one pass in ECAP.

For comparison purposes, a billet of Al-1050 aluminium (99.5\% pure Al) was also pressed for one pass at room temperature and the texture evaluated using EBSD.

\section{Experimental results}

An EBSD grain boundary map in shown in Fig. 2(a) for the centre area of the crosssection on a plane perpendicular to the $\mathrm{X}_{0}$ direction: henceforth, this is termed the $\mathrm{X}_{0}$ section plane. In Fig. 2(a) the dark and grey lines represent high-angle grain boundaries (HAGBs with misorientation angles $>15^{\circ}$ ) and low-angle grain boundaries (LAGBs with misorientation angles in the range of $2-15^{\circ}$ ), respectively. Figure 2(b) shows a plot of the frequency distribution of the misorientation angles with a superimposed theoretical distribution for an aggregate of randomlyoriented grains. The large difference between the two frequency distributions demonstrates that the as-received alloy contains a strong textures. Moreover, a sharp peak around $55^{\circ}$ is noticeable. Figures $2(\mathrm{c})$ and (d) show $\{100\}$ and $\{111\}$ pole figures projected on the $\mathrm{X}_{0}$ section plane and the $\mathrm{Z}_{0}$ section plane, respectively. These pole figures reveal strong $\left.<111\right\rangle+<100>$ double fibre textures along the axis of the as-received billet which are a direct consequence of the conventional extrusion.

After a single pass of ECAP, the material contains a relatively high fraction of LAGBs compared to the as-received alloy, as shown by the grey lines in Fig. 3(a). The corresponding frequency distribution of the misorientation angles, shown in Fig. 3(b), confirms the predominance of LAGBs. The total area fraction of these LAGBs is $\sim 68 \%$ after the first pass and this compares to $\sim 35 \%$ in the as-received alloy. Thus, a single pressing leads to the introduction of an array of sub-grain boundaries with misorientations less than $15^{\circ}$. The EBSD data were also acquired in other positions on the cross-section of the billet axis. Fig. 3(c) shows the $\{100\}$ and $\{111\}$ pole figures for a variety of positions on the $\mathrm{X}$ plane cross-section. These pole figures are represented on the $\mathrm{Z}$ section plane as shown in Fig. 4. From the similarity of most of these patterns, it is deduced that about $90 \%$ of the billet deforms in a very similar manner, with a small region at the edge of the billet that passed through the outer intersections of the channels (encompassing $\mathrm{S}_{5}$ and $\mathrm{S}_{6}$ ) showing evidence for a different deformation history. It is important to 
record also that earlier analyses of the microstructures produced in this alloy by ECAP revealed the formation and subsequent coarsening of small disc-shaped $\eta$-phase precipitates [15] and the fragmentation during pressing of the coarse rod-shaped $\eta$-phase precipitates $[16,17]$.

\section{An analysis of texture}

\subsection{Predominant shear-induced textures}

Recent TEM results [18] provide clear evidence for the existence of two shear planes: deformation during ECAP occurs both parallel to the main shear plane (MSP) as well as on the plane perpendicular to the MSP: this means that, using the notation in Fig. 1(b), shear occurs on the $\mathrm{Y}^{\prime}$ section plane as the MSP and the $\mathrm{X}^{\prime}$ section plane as the secondary shear plane (SSP). The direction of the shear lies in the plane of symmetry of the die (the plane normal to $\mathrm{X}^{\prime}$ and $\mathrm{Y}^{\prime}$ ). To explain the observed textures, it is necessary to take the orientations $\mathrm{A}, \mathrm{B}$ and $\mathrm{C}$ for shearing on both the main and secondary shear planes: the details are summarised in Table 2. As will be demonstrated in the analysis, the $A^{*}\{111\}<11 \overline{2}>$ system is not required in order to explain the observed textures.

Figure 5(a) shows the $\{100\}$ and (111\} pole figures for the A, B and C orientations projected on the MSP (the $\mathrm{Y}^{\prime}$ section plane) and Fig. 5(b) shows pole figures of the A, B and C orientations for shearing on the SSP ( $\mathrm{X}^{\prime}$ section plane) perpendicular to MSP. Figure 5(c) represents these orientations on the $Z^{\prime}$ section plane. Using the simple shear plane assumption, it has been shown that, for an ECAP die having an angle of $\Phi=90^{\circ}$ between the two channels, the shear plane is ideally rotated by $45^{\circ}$ around the $Z^{\prime}$ axis [12,13]. This rotation is therefore incorporated into Fig. 5(d).

Figure 6(a) shows the experimental pole figures for position $S_{3}$ in Fig. 4. Thus, by comparing Fig. 6(a) and Fig. 5(d), the experimental pole figures based on the EBSD data appear to be rotated by $50^{\circ}$ and this represents a small deviation from the ideal rotation of $45^{\circ}$. Figure 6 (b) shows the predicted pole figures with only the three strongest shear systems present, where this corresponds to orientations A, C on MSP and orientation A on SSP rotated by $50^{\circ}$ from Fig. 5(c). This representation demonstrates an excellent match with the experimental data in Fig. 6(a), thereby confirming that the measured pole figures may be fully explained in terms of three shear systems: there are extensive A and C shear systems shearing on MSP (high density in the pole figures) and a weaker A orientation shearing on the secondary shear plane (low density in the pole figures). There is no evidence for the $\mathrm{B}$ shear system on either of these shear planes. Furthermore, it is not necessary to consider the initial texture of the billet because it is evident that the intense shear deformation imposed in ECAP erases almost all evidence of this earlier texture. In a subsequent analysis, the $A^{*}$ shear system was specifically considered but it was found that the inclusion of the A shear system on the SSP covers all intensity maxima previously attributed to $A^{*}$. It is reasonable to conclud, therefore, that there is no evidence for the occurrence of the $A^{*}$ system.

\subsection{Texture development at the outer corner of the die (positions $S_{5}$ and $S_{6}$ in Fig. 4)}

At the outer corner of the die, substantial contact friction may exist between the channel wall and the billet. Modelling of deformation predicts these areas experience a deformation that is significantly different from the shear-dominated zone within the bulk of the billet $[19,20]$. As anticipated, the EBSD measurements reveal different textures as documented in Fig. 4.

The pole figures of the experimental EBSD data in position $\mathrm{S}_{5}$ is given in Fig. 7(a) and Fig. 7(b) shows a simulated pole figure with extensive Copper and relatively weak Goss rolling textures. A comparison shows there is an excellent match between the simulated and experimental data. However, it should be noted that the present form of orientation $\{225\}<554>$ deviates about $5.8^{\circ}$ from the ideal Copper texture $\{112\}<111>$. 
Figure 8(a) shows the $\{100\}$ and (111\} pole figures of the EBSD data at the outer edge of the billet in position $\mathrm{S}_{6}$ and Fig. 8(b) gives the simulated pole figures with textures of Copper and Cube as shown in Table 3. The pole figures are explained well by the rolling texture of Copper and the weak texture of Cube. Furthermore, compared to Fig. 7, the Goss texture observed in position $\mathrm{S}_{5}$ has now disappeared. In practice, the Cube texture is normally regarded as the recrystallisation texture and this suggests the occurrence of some weak recrystallisation at the outermost edge of the billet during ECAP at $473 \mathrm{~K}$. It is interesting to note that the density for the Copper texture is not symmetric. It appears that one Copper component is substantially stronger than the opposite Copper component due to the sense of the shear direction during ECAP.

As shown with finite element analyses, the use of ECAP dies having arcs of curvature of $\psi \approx 20-30^{\circ}$ leads to a zone with a different deformation pattern in a region at the lower edge of the billet where it passes through the zone of intersection of the channels [19,20]. In this zone, the total plastic strain is reduced and, in addition, the plastic deformation strain is increased with increasing friction between the billet and the adjacent die wall $[9,21,22]$. The present analysis shows that, while this narrow zone experiences deformation that is significantly different from the major part of the billet, it nevertheless undergoes deformation that is sufficiently large to create a characteristic texture.

\section{Discussion}

\subsection{Factors influencing the deviation from the ideal angle and texture evolution}

In the present investigation, it is shown that ECAP of an Al-7034 alloy leads to a deviation of $5^{\circ}$ from the ideal value predicted for simple shear during ECAP. The reason for this deviation is not clear but this is a heat-treatable alloy containing a high volume fraction of intermetallic particles having a range of sizes [23,24]. For comparison purposes, an Al-1050 (99.5\% pure $\mathrm{Al}$ ) aluminium billet was processed by ECAP at room temperature using an ECAP die with the same geometry. This material contained a similar but weaker as-received $<111>+$ $<100>$ texture as shown in Fig. 9(a) and ECAP for one pass led to the same deviation angle of $5^{\circ}$ as shown in Fig. 9(b). The close similarity between Al-7034 and Al-1050 demonstrates that alloy strength, the formation of second phase particles and the development and fragmentation of precipitates during ECAP are not significant factors in determining the deviation from an ideal condition.

It is important to note that deviation angles of $10-20^{\circ}$ from the ideal by simple shear were reported earlier in the ECAP of $\mathrm{Cu}[18]$ and $\mathrm{Al}[11,25]$. It was proposed that the deviation may change with the strain compression component [25]. Experiments also confirmed that the deviation depends on the arc of curvature at the outer intersection of the two channels and on the die-wall friction [11]. Precipitate fragmentation has also been suggested as a contributing factor influencing the deviation from an ideal angle by simple shear [26]. However, since the deviation depends on the arc of curvature, $\psi$, at the outer intersection of the two channels [11], it is probable that the zone of heavy shear is not confined to a single plane, as considered in the idealised case, but rather it extends on either side causing a slight rotation of the MSP. This can explain the reported small deviations from the case of a single shear plane.

\subsection{Texture evolution during shear deformation: the significance of the shear systems}

The amount of grain rotation during intensive shear deformation depends on a number of factors: it increases both with increasing flow shear strength on crystallographic slip systems and with decreasing grain size. Compared with other alloys investigated in ECAP, the present alloy is relatively strong with a small initial grain size. Hence, grain rotation is promoted, which in turn promotes the development of clearly defined texture components as observed in Figs. 3 and 4. 
In shear deformation of aluminium and aluminium alloys, normally there is an activation of the ideal shear components $\{111\}<110>,\{100\}<110>,\{112\}<110>[14,27,28]$. In practice, the evolution of texture during ECAP has been well predicted using these three shear systems plus the $\{111\}<112>A^{*}$ system $[8,10,29,30]$. However, the activation of the $A^{*}$ shear system is questionable because there is no evidence directly confirming the existence of the $<112>$ Burgers vector in aluminium alloys at strains up to 4 . In addition, a study of texture evolution in $\mathrm{Cu}$ during ECAP suggested that the shear direction is essentially in the close-packed direction of $<110>$ for f.c.c. crystals [29]. It might be worth adding here that $1 / 6<112>$ partial dislocations linked to stacking faults have been reported in deformed $\mathrm{Cu}$ alloys with 11 to 16 at.\% $\mathrm{Al}[31,32]$. This is related to a very low stacking fault energy in these binary $\mathrm{Cu}-\mathrm{Al}$ alloys. However, $\mathrm{Al}$ and Al alloys possess a high stacking fault energy and there is no report or observation for the existence of stacking faults in $\mathrm{Al}$ and $\mathrm{Al}$ alloys. Thus this $1 / 6<112>$ partial dislocation should not occur in $\mathrm{Al}$ and $\mathrm{Al}$ alloys.

To evaluate the precise significance of the $\mathrm{A}^{*}$ system in ECAP, it is necessary to examine the nature of the supporting data for the occurrence of this system.

The original claim for the existence of an $\mathrm{A}^{*}$ orientation lies in an investigation based on texture data derived from torsion testing of $\mathrm{Al}$ where a very faint maxima relating to $\mathrm{A}^{*}$ was reported for one test only [14]. In this single test, the strain level was $\sim 5$ which is higher than in the present investigation for pressing by one pass of ECAP. In addition, the test was conducted at room temperature whereas the Al-7035 alloy was pressed at $473 \mathrm{~K}$. At all other temperatures from 473 to $673 \mathrm{~K}$ and at all other strain levels from $\sim 0.6$ to $\sim 2.2$, the A* system was absent. Thus, the available evidence suggests that the $\mathrm{A}^{*}$ system is not activated in $\mathrm{Al}$ at the shear strains relevant to a single pass in ECAP. In the preceding section, it was shown that the existence of a secondary shear plane perpendicular to MSP, as indicated in TEM studies [18], eliminates the necessity of assuming this unlikely shear system. Furthermore, the texture evolution obtained in the present investigation is well explained using an accepted and intuitively reasonable selection of shear systems which are known to be activated in controlled shear tests on aluminium. In the present analysis, $\{111\}<110>$ slip evolves in both the MSP and the SSP whereas the $\{001\}<110>$ shear system occurs on the MSP only. There is no evidence for the occurrence of $\{112\}<110>$ slip.

Following this analysis of the present experiments and data available for torsion tests $[14,33,34]$, it is now possible to delineate a sequence of slip plane activations in the shear of aluminium alloys at temperatures up to $\sim 473 \mathrm{~K}$, as shown in Table 4 . In addition, Table 4 adds data for shears strains of 10 and larger obtained at high temperatures of $\sim 573-673 \mathrm{~K}$. It is apparent that the shear system activation in ECAP is consistent with the data available for conventional torsion testing provided the SSP is also considered in the analysis. Furthermore, the results are encouraging because they indicate that only two shear systems (A and C) are contributing in the processing of aluminium by ECAP.

\section{Summary and conclusions}

1. An analysis of an Al-7034 alloy processed for one pass by ECAP shows the texture is consistent with grains rotating to align the crystallographic shear planes and directions to accommodate shearing on two macroscopic shear planes: one is the main shear plane determined by simple shear theory and the other is a secondary shear plane which is perpendicular to the main shear plane. The $\{111\}<110>$ and $\{001\}<110>$ shear systems both occur. The former shears on both shear planes but the latter shears only on the main shear plane.

2. In a small region at the lower edge where the billet passes through the zone of intersection of the channels, the observed textures are Copper and/or Goss textures rolled on the Y section plane. 


\section{Acknowledgement}

The work was funded in part by EPSRC under Grant No. EP/D00313X/1.

\section{References}

1. Valiev RZ, Langdon TG. Prog. Mater Sci 2006;51:881.

2. Furukawa M, Iwahashi Y, Horita Z, Nemoto M, Langdon TG. Mater Sci Eng A 1998;257:328.

3. Gholinia A, Prangnell PB, Markushev MV. Acta Mater 2000;48:1115.

4. Furukawa M, Horita Z, Nemoto M, Langdon TG. J Mater Sci 2001;36:2835.

5. Nakashima K, Horita Z, Nemoto M, Langdon TG. Acta Mater 1998;46:1589.

6. Prangnell PB, Harris C, Roberts SM, Scripta Mater. 1997;37:983

7. Figueiredo RB, Cetlin PR, Langdon TG. Acta Mater 2007;55:4769.

8. Li S, Beyerlein IJ, Alexander DJ, Vogel SC. Acta Mater 2005;53:2111.

9. Li S, Beyerlein IJ, Necker CT, Alexander DJ, Bourke M. Acta Mater 2006;54:1397.

10. Zhilyaev AP, Swisher DL, Oh-ishi K, Langdon TG, McNelley TR. Mat Sci Eng A 2006;429:137.

11. Zhilyaev AP, Oh-ishi K, Raab GI, McNelley TR. Mat Sci Eng A 2006;441:245.

12. Segal VM, Mater Sci Eng A 1995; 197:157.

13. Segal VM, Mater Sci Eng A 1999;271:322.

14. Montheillet F, Cohen M, Jonas JJ. Acta Metall 1984;32:2077.

15. Wang SC, Starink MJ, Gao N, Xu C, Langdon TG. Rev Adv Mater Sci 2005;10:249.

16. Xu C, Furukawa M, Horita Z, Langdon TG. Acta Mater 2003;51:6139.

17. Xu C, Furukawa M, Horita Z, Langdon TG, Acta Mater 2005; 53:749-758..

18. Xue Q, Beyerlein IJ, Alexander DJ, Gray III GT. Acta Mater 2007;55:655.

19. Wu Y, Baker I. Scripta Mater 1997;37:437.

20. Li S, Beyerlein IJ, Necker CT, Alexander DJ, Bourke M. Acta Mater 2004;52:4859.

21. Kim HS, Seo MH, Hong SI. Mater Sci Eng A 2000;291:86.

22. Semiatin SL, DeLo DP, Shell EB. Acta Mater 2000;48:1841.

23. Starink MJ, Wang SC. Acta Mater 2003;51:5131.

24. Gao N, Starink MJ, Furukawa M, Horita Z, Xu C, Langdon TG, Mater Sci Eng A, 2005;410411:303.

25. Gholinia A, Bate P, Prangnell PB. Acta Mater 2002;50:2121.

26. Chowdhury SG, Xu C, Langdon TG. Mater Sci Eng A 2007;473:219.

27. Kocks UF, Tome CN, Wenk HR. Texture and Anisotropy. Cambridge University Press, Cambridge. U.K., 1998.

28. Canova GR, Kocks UF, Jonas JJ. Acta Metall 1984;32:32.

29. Huang WH, Chang L, Kao PW, Chang CP. Mat Sci Eng A 2001;307:113.

30. Gazder AA, Li S, Dalla Torre FH, Beyerlein IJ, Gu CF, Davies CHJ, Pereloma EV. Mater Sci Eng A 2006;437:259.

31. Mori T, Fujita, H. Acta Metall. 1980;28:771.

32. Inui H, Hong SI, Laird C. Acta Metall Mater 1990;38: 2261.

33. Martins RV, Lienert U, Margulies L, Pyzalla A. Mater Sci Eng A 2005;402:278

34. Canova GR, Kocks UF, Jonas JJ. Acta Metall 1984;32:211. 
Fig. 1 (a) Schematic illustration of a billet before and after a single pressing through the die; (b) the coordinate systems.

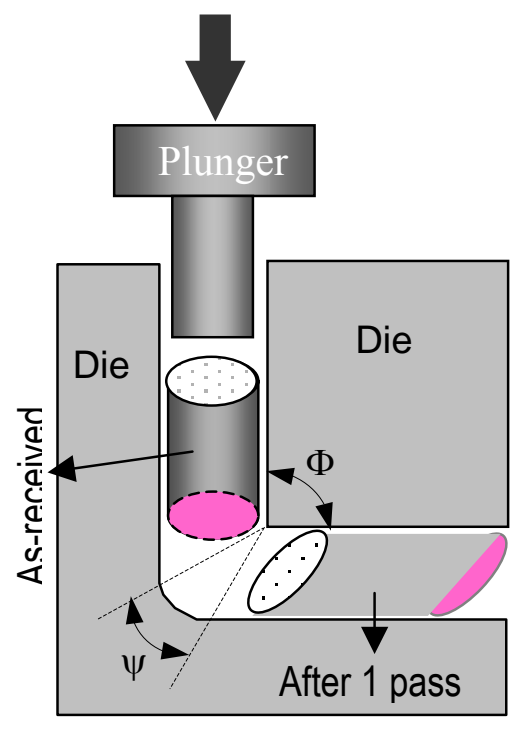

(a)

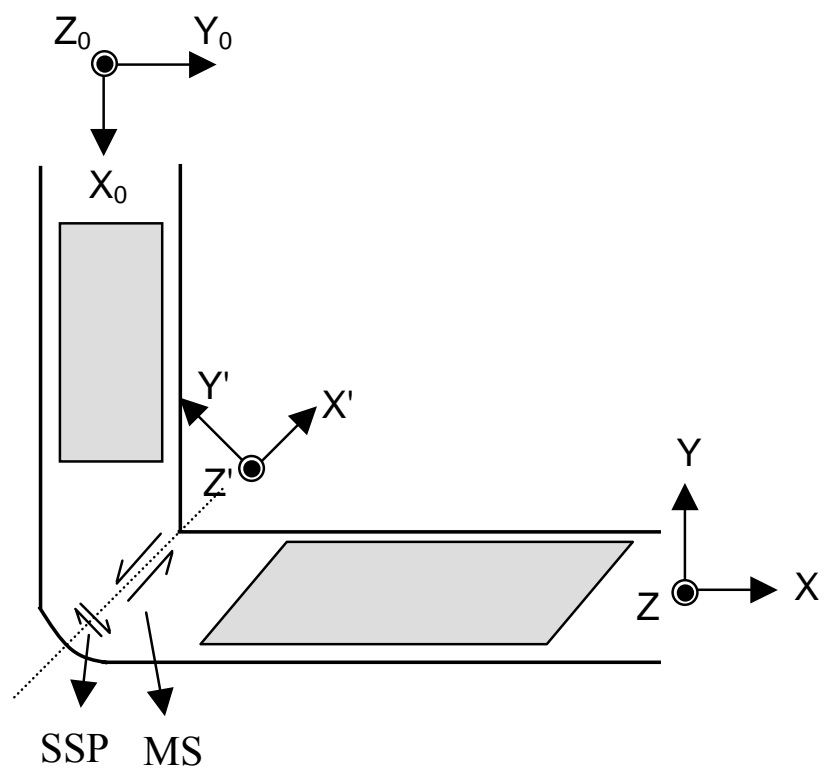

(b) 
Fig. 2 EBSD data of the Al-7034 alloy in the as-received condition (centre of billet): (a) grain boundary map from $\mathrm{X}_{0}$ section plane; dark and grey lines represent HAGBs $\left(>15^{\circ}\right)$ and LAGBs, respectively; (b) the frequency distribution vs. misorientation angles; (c) $\{100\}$ and $\{111\}$ pole figures viewed from $\mathrm{X}_{0}$ section plane; (d) $\{100\}$ and $\{111\}$ pole figures viewed from $\mathrm{Z}_{0}$ section plane.

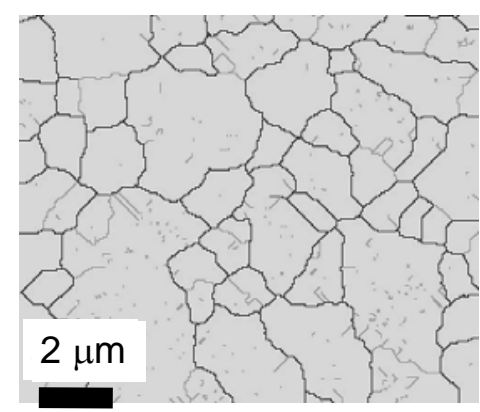

(a)

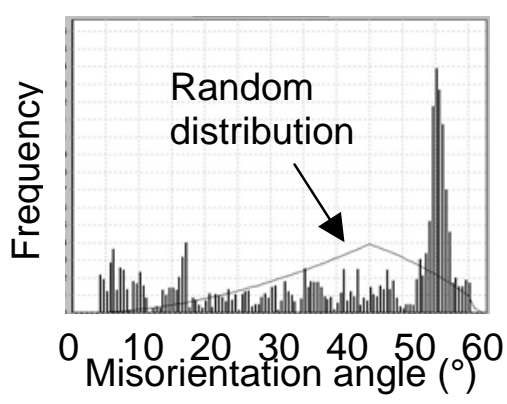

(b)

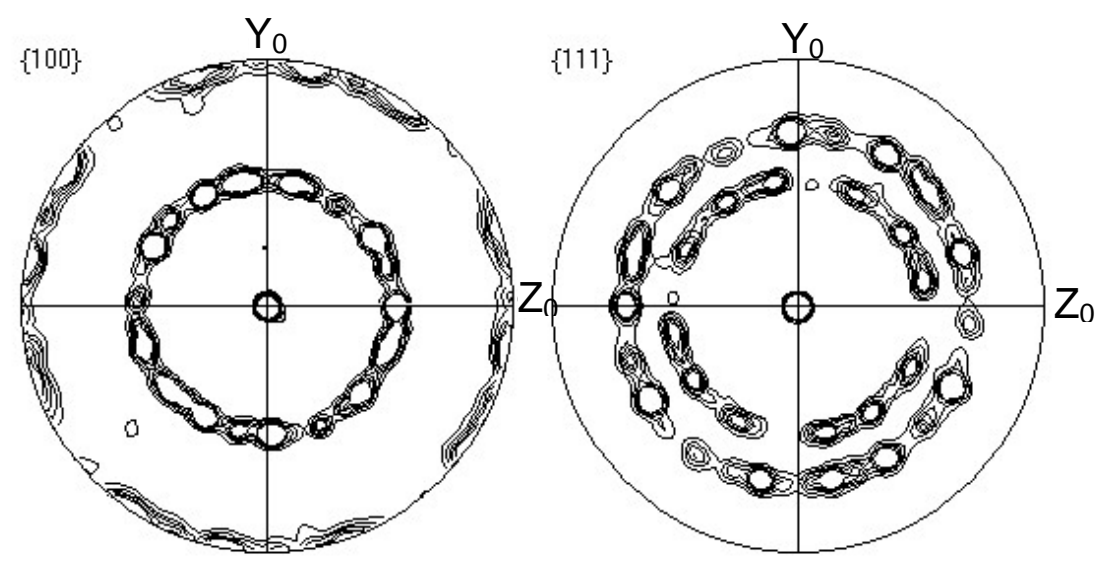

(c)

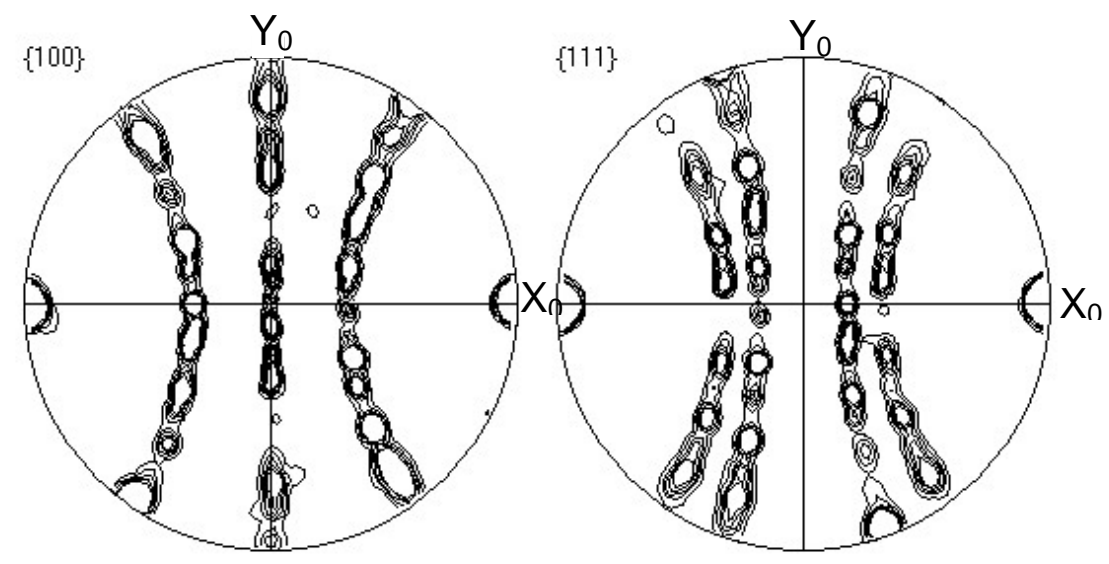

(d) 
Fig. 3 EBSD data acquired after 1 pass of ECAP of the Al-7034 alloy: (a) grain boundary map in X section plane, close to the centre of the billet; dark and grey lines represent HAGBs and LAGBs, respectively, (b) the corresponding frequency distribution vs misorientation angles and (c) mapping of $\{111\}$ pole figures located in different areas after 1 pass of ECAP acquired from the X-Y plane shown in Fig. 1.

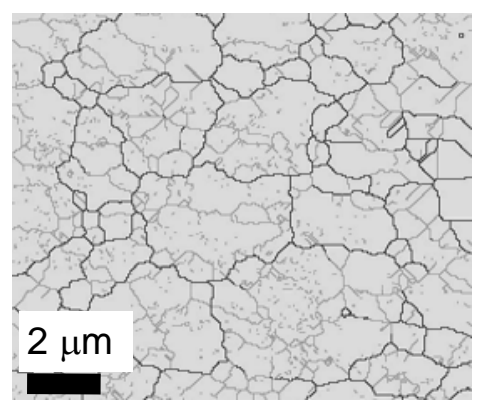

(a)

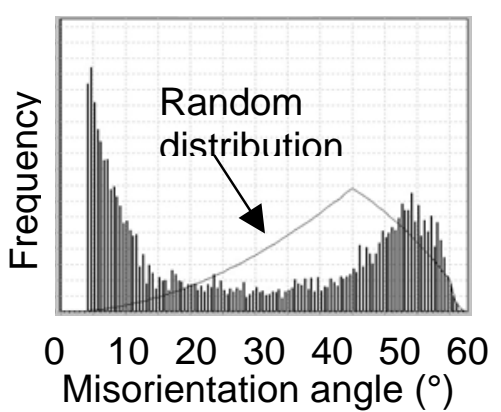

(b)

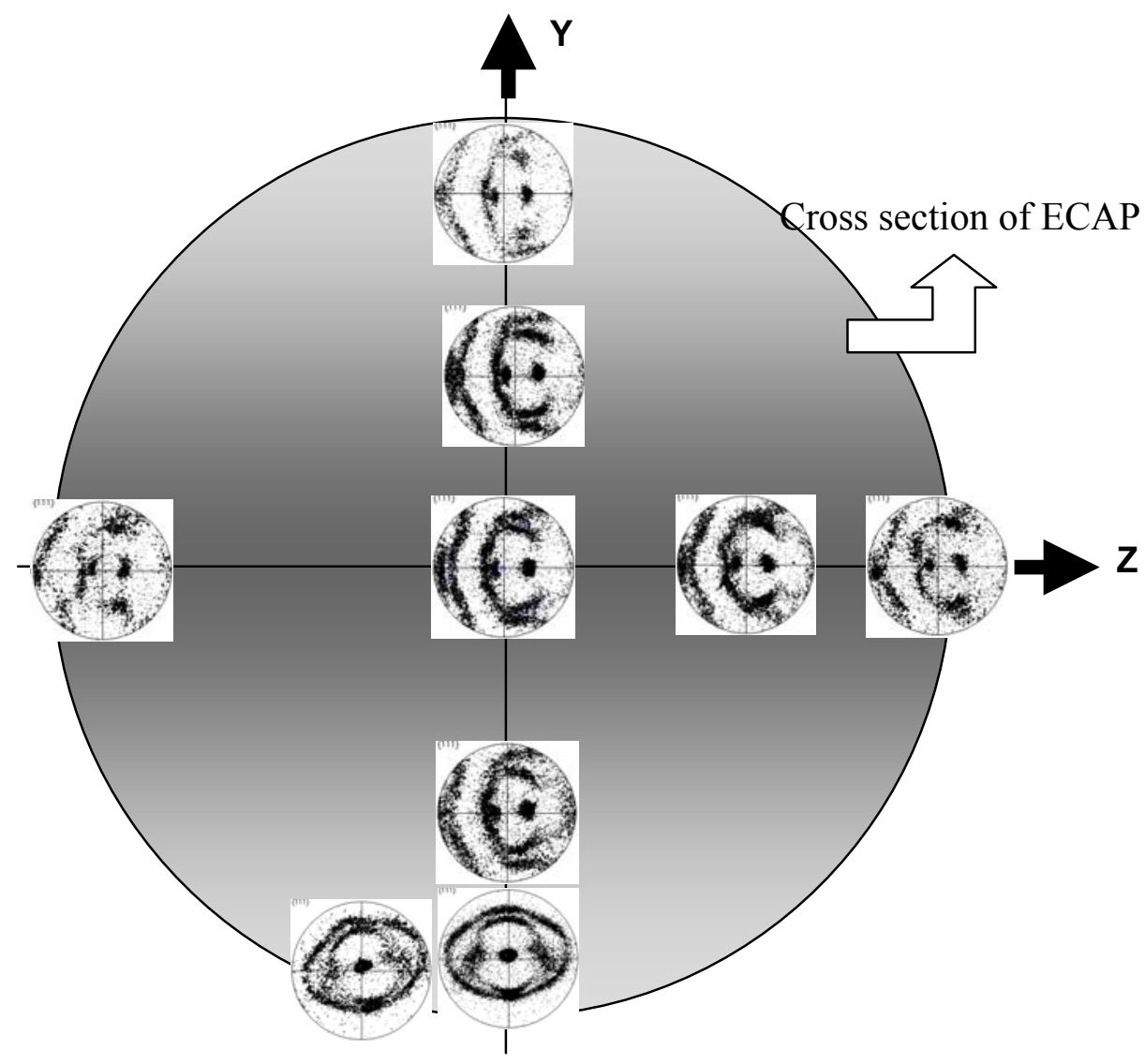

(c) 
Fig. 4 Mapping of $(100\}$ and $\{111\}$ pole figures viewed in $Z$ section plane at different positions of the Al-7034 alloy billet after 1 pass of ECAP: $\mathrm{S}_{\mathrm{i}}$ represents the distance from the top surface of the billet normalised by the billet diameter.
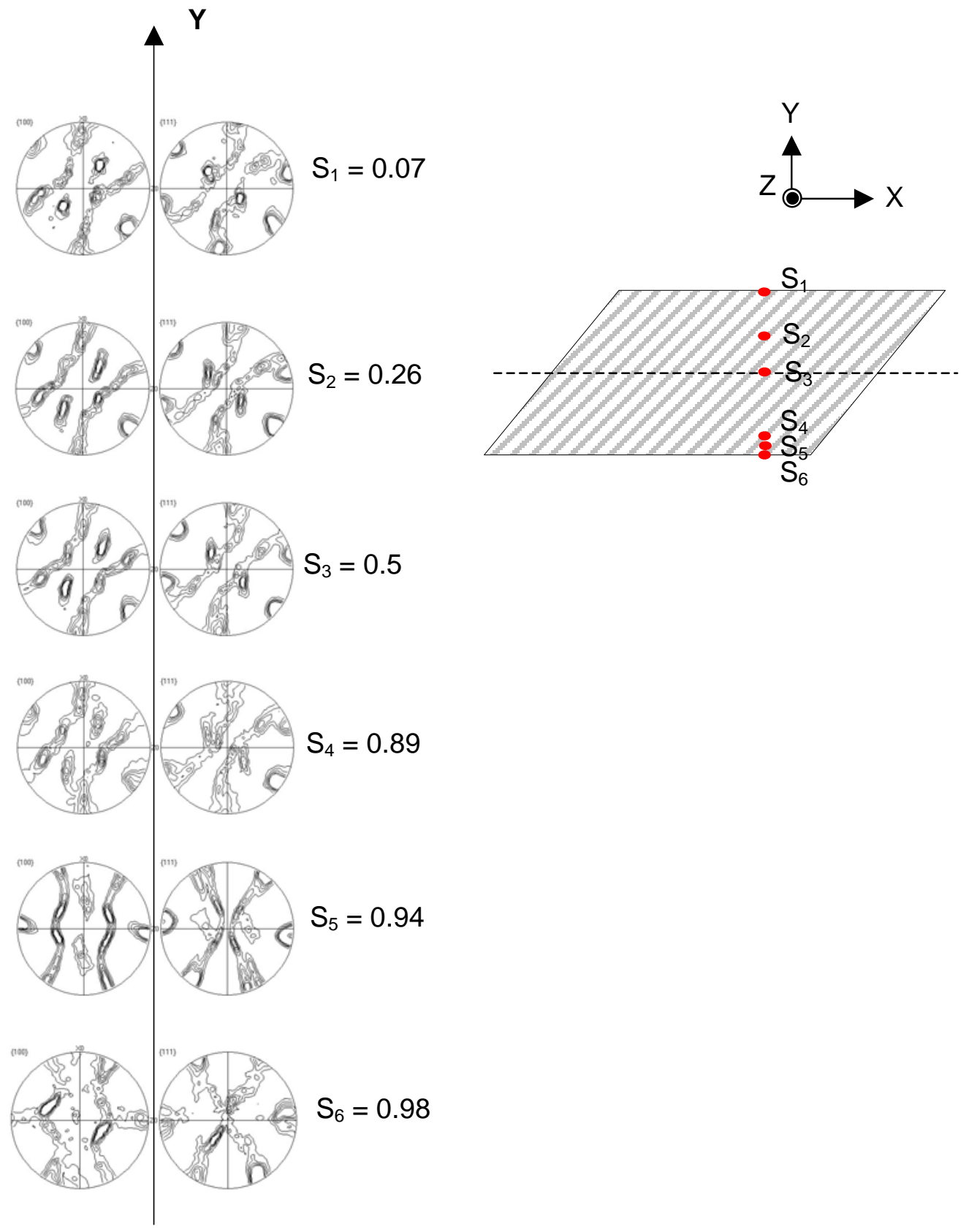
Fig. $5\{100\}$ and $\{111\}$ pole figures of the of the Al-7034 alloy after one ECAP pass showing: (a) the main ideal orientations associated with shearing on $\mathrm{Y}^{\prime}$ section plane parallel to MSP, (b) the $X^{\prime}$ section plane perpendicular to MSP, (c) the orientations in Table 2 projected in $Z^{\prime}$ section plane of $X^{\prime}-Y^{\prime}$ coordinates; and (d) the $Z$ section plane of the $X-Y$ coordinates.
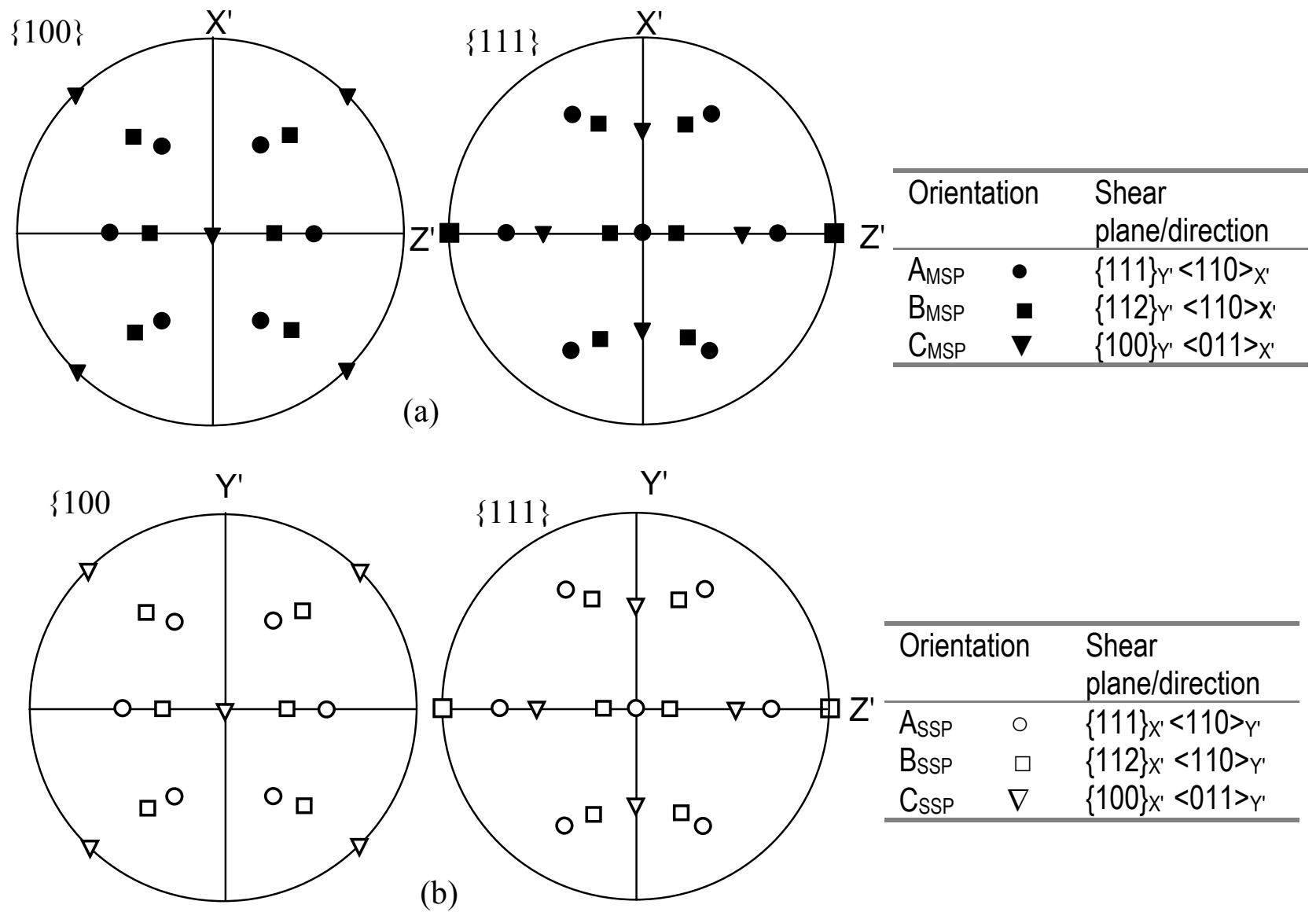

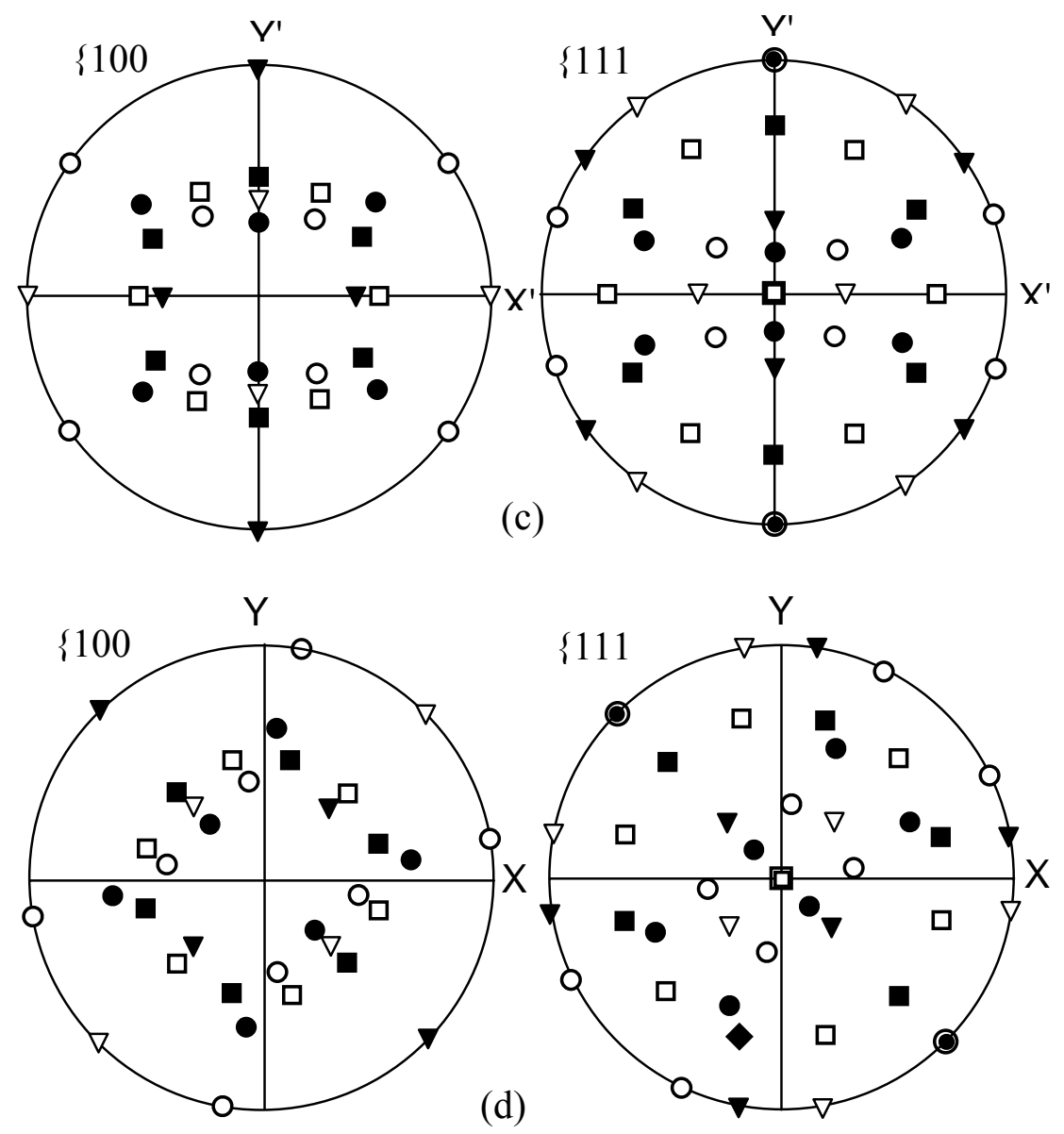
Fig. 6 (a) Experimental data for position $\mathrm{S}_{3}$ in Fig. 4, and (b) the $\mathrm{X}-\mathrm{Y}$ coordinates rotated by $50^{\circ}$ from $X^{\prime}-Y^{\prime}$ coordinates in Fig. 5c (only the existing orientations are shown)
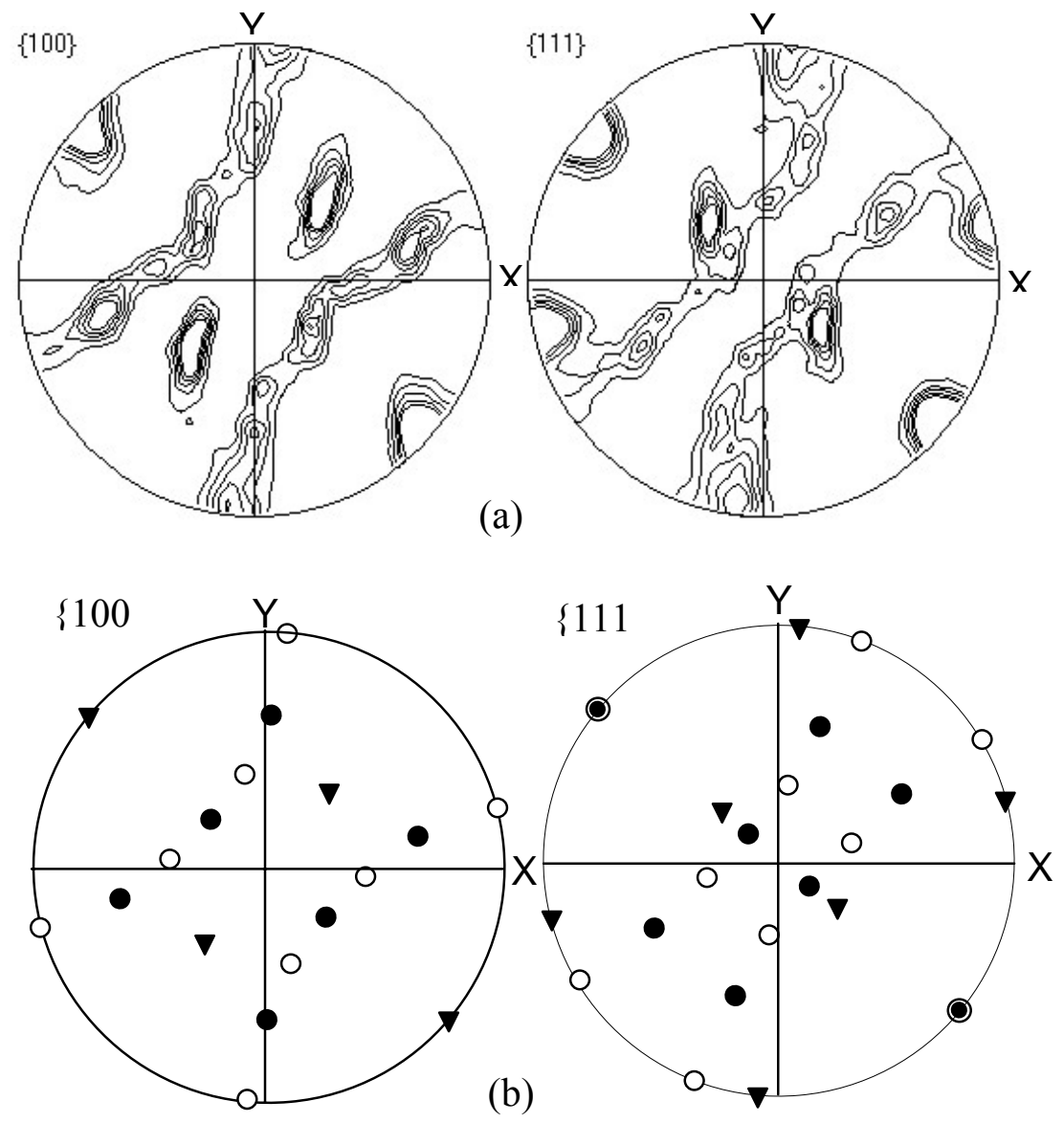

\begin{tabular}{|c|c|c|}
\hline \multicolumn{2}{|c|}{ Orientation } & Shear plane/direction \\
\hline$A_{M S P}$ & $\bullet$ & $\{111\}_{Y^{\prime}}<110>_{X^{\prime}}$ \\
\hline $\mathrm{C}_{\mathrm{MSP}}$ & $\nabla$ & $\{100\} Y^{\prime}<011>X^{\prime}$ \\
\hline AssP & O & $\{111\}_{X^{\prime}}<110>_{Y^{\prime}}$ \\
\hline
\end{tabular}


Fig. $7\{100\}$ and $\{111\}$ pole figures on the $\mathrm{Y}$ section plane for position $\mathrm{S}_{5}$ obtained from (a) EBSD data; and (b) ideal textures of Copper and Goss orientations.

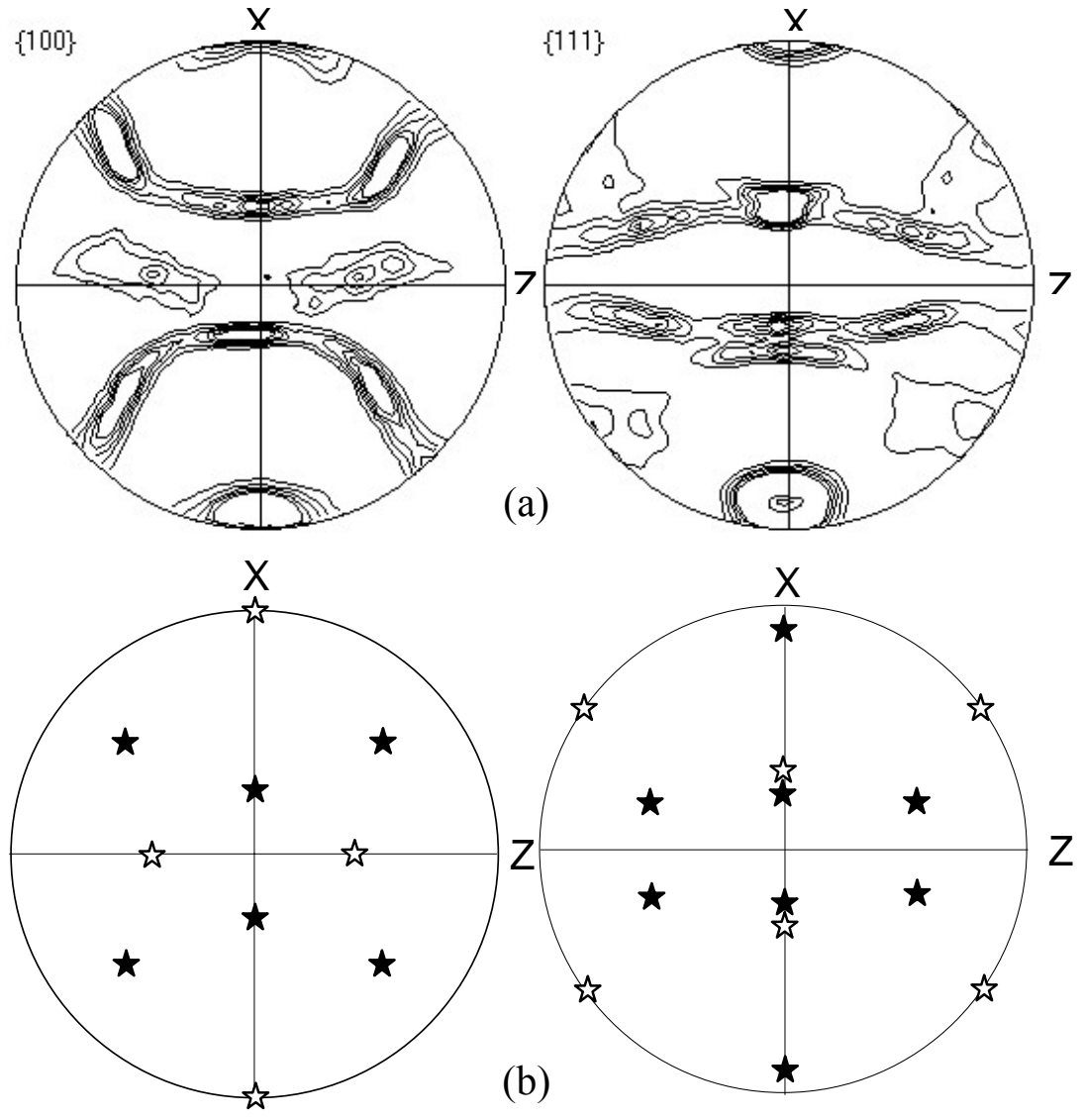

\begin{tabular}{|c|c|c|}
\hline Textures & & Orientation \\
\hline $\begin{array}{l}\text { Copper } \\
\text { Goss }\end{array}$ & 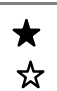 & $\begin{array}{l}\{225\}_{Y}<554>_{X} \\
\{011\}_{Y}<100>_{X}\end{array}$ \\
\hline
\end{tabular}


Fig. $8\{100\}$ and $\{111\}$ pole figures on the $\mathrm{Y}$ section plane for position $\mathrm{S}_{6}$ obtained from (a) EBSD data; and (b) ideal textures of Copper and Cube orientations.
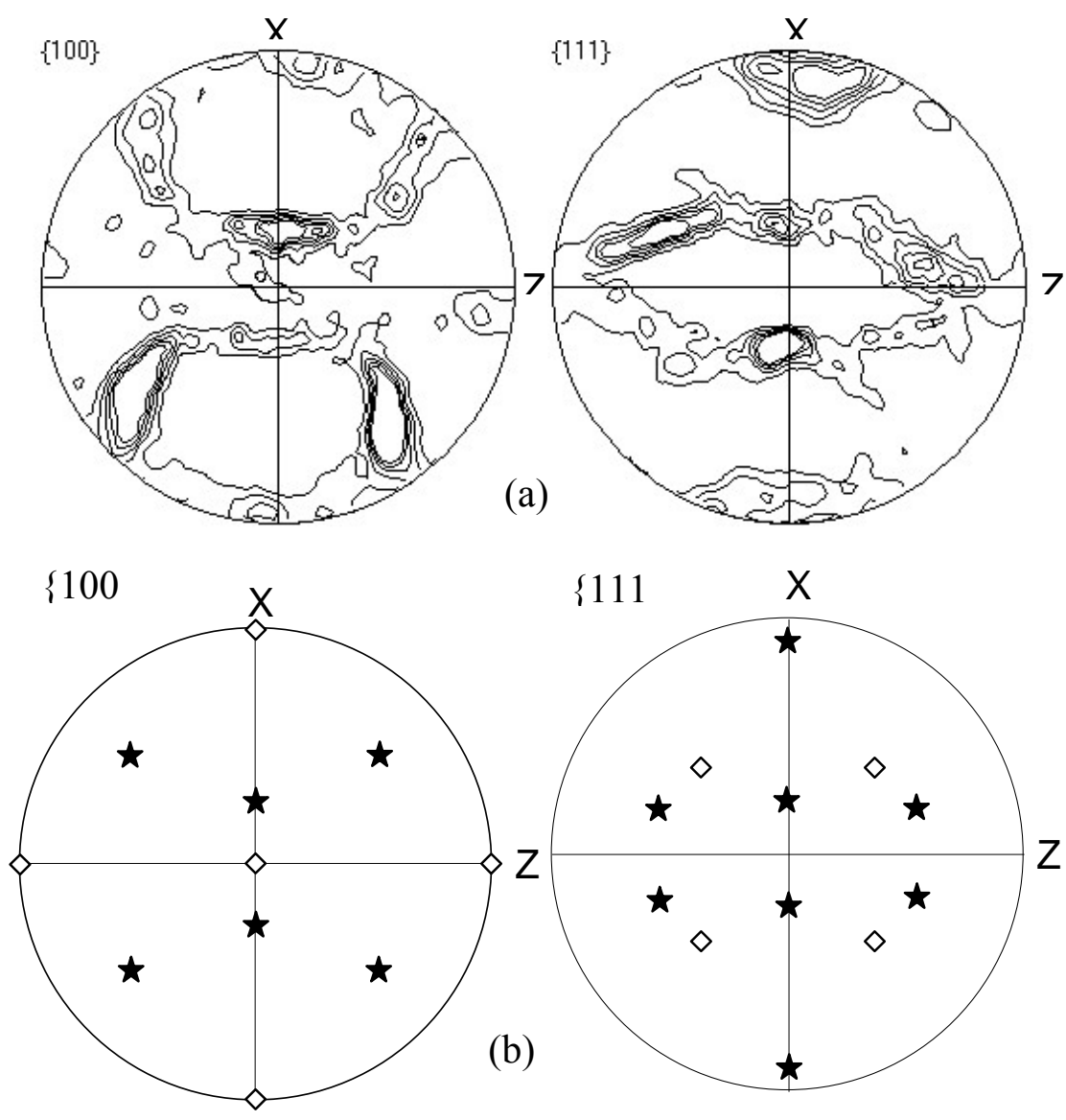

\begin{tabular}{lll}
\hline Textures & & Orientation \\
\hline Copper $\star$ & $\{225\}_{Y}<554>_{X}$ \\
Cube $\diamond \diamond$ & $\{001\}_{Y}<100>_{X}$ \\
\hline
\end{tabular}




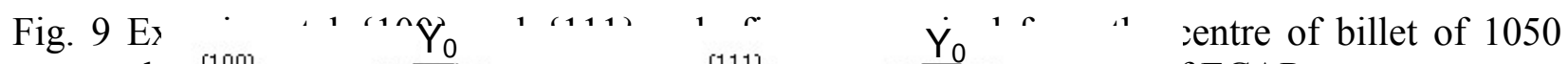
alı $\{100\}$
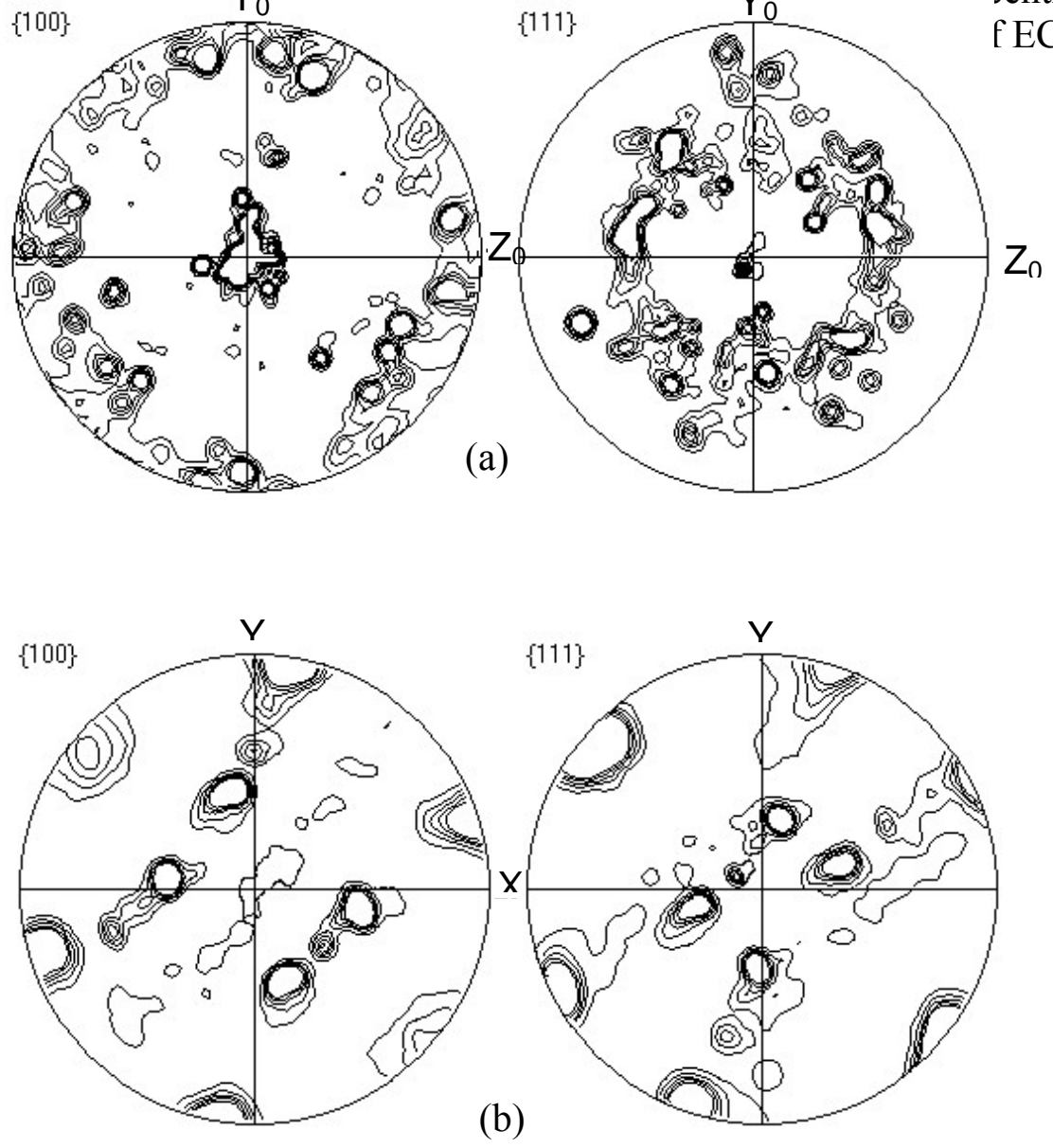
Table 1 Shear systems used in the modelling of f.c.c. structures including Al alloys [14]

\begin{tabular}{c|c}
\hline Symbol & Shear plane/direction \\
\hline A & $\{111\}<\overline{1} 10>$ \\
A $^{*}$ & $\{111\}<11 \overline{2}>$ \\
B & $\{112\}<\overline{1} 10>$ \\
C & $\{001\}<110>$ \\
\hline
\end{tabular}

Table 2 Possible shear textures in the MSP ( $Y^{\prime}$ section plane) and the SSP ( $\mathrm{X}^{\prime}$ section plane)

\begin{tabular}{c|c|c}
\hline Symbol & Shear plane & Shear direction \\
\hline $\mathrm{A}_{\mathrm{MSP}}$ & $\{111\}$ on $\mathrm{Y}^{\prime}$ section plane & $<\overline{1} 10>$ on $\mathrm{X}^{\prime}$ direction \\
$\mathrm{B}_{\mathrm{MSP}}$ & $\{112\}$ on $\mathrm{Y}^{\prime}$ section plane & $<\overline{1} 10>$ on $\mathrm{X}^{\prime}$ direction \\
$\mathrm{C}_{\mathrm{MSP}}$ & $\{001\}$ on $\mathrm{Y}^{\prime}$ section plane & $<110>$ on $\mathrm{X}^{\prime}$ direction \\
$\mathrm{A}_{\mathrm{SSP}}$ & $\{111\}$ on $\mathrm{X}^{\prime}$ section plane & $<\overline{1} 10>$ on $\mathrm{Y}^{\prime}$ direction \\
$\mathrm{B}_{\mathrm{SSP}}$ & $\{112\}$ on $\mathrm{X}^{\prime}$ section plane & $<\overline{1} 10>$ on $\mathrm{Y}^{\prime}$ direction \\
$\mathrm{C}_{\mathrm{SSP}}$ & $\{001\}$ on $\mathrm{X}^{\prime}$ section plane & $<110>$ on $\mathrm{Y}^{\prime}$ direction \\
\hline
\end{tabular}


Table 3 Textures appearing at the outer corner of the die (Position 6)

\begin{tabular}{ll}
\hline Textures & Orientation \\
\hline Copper & $\{225\}_{Y}<554>_{X}$ \\
Cube & $\{001\}_{Y}<100>_{X}$ \\
\hline
\end{tabular}

Table 4 Proposed shear system activation during shear of Al at low temperatures (up to $473 \mathrm{~K}$ ) for shear strains up to 5 and at high temperatures $(573$ to $673 \mathrm{~K})$ for shear strains in excess of 10 .

\begin{tabular}{|c|c|c|}
\hline $\begin{array}{c}\text { Shear strain } \\
\text { (approximate } \\
\text { range) }\end{array}$ & Shear systems & Typical cases \\
\hline $0-0.5$ & $\{111\}<\overline{1} 10>(=\mathrm{A})$ & $\begin{array}{l}\text { Low deformation torsion } \\
\text { tests[14], SSP in ECAP }\end{array}$ \\
\hline $0.5-3$ & $\{111\}<\overline{1} 10>(=\mathrm{A})+\{001\}<110>(=\mathrm{C})$ & $\begin{array}{l}\text { MSP in ECA (shear strain } \\
\text { about } 1 \text { ), torsion test }\left[14,31^{\dagger}\right]\end{array}$ \\
\hline$\sim 5$ & $\{001\}<110>(\mathrm{C})\left(+\mathrm{A}^{*} ?\right)$ & $\begin{array}{l}\text { High deformation torsion tests } \\
\qquad[14,32]\end{array}$ \\
\hline $\begin{array}{c}>10 \\
(\text { at } 573-673 \mathrm{~K})\end{array}$ & $\{112\}<110>(B)$ & $\begin{array}{l}\text { High deformation torsion tests } \\
\qquad[14]\end{array}$ \\
\hline
\end{tabular}

$\dagger$ An additional orientation $\mathrm{A}^{*}$ was observed but it is suggested this may be due to A in a SSP. 